\title{
THE SCOTT WIRING TECHNIQUE FOR DIRECT REPAIR OF LUMBAR SPONDYLOLYSIS
}

\author{
G. V. JOHNSON, A. G. THOMPSON
}

From the Royal Orthopaedic Hospital, Birmingham

\begin{abstract}
Between 1979 and 1989, we treated 22 patients with symptomatic lumbar spondylolysis which had not responded to conservative treatment by a modified Scott wiring technique to give direct repair of the lytic defects with stabilisation. The patients' mean age at the time of operation was 15 years; the mean follow-up period was four years. All 19 patients under 25 years old had satisfactory results. Two of the three patients over 25 years old had poor results.

The age of the patient at surgery seems to be an important determinant of outcome. Radiologically confirmed fusion is of secondary importance. The presence of a grade I spondylolisthesis did not prejudice the result.
\end{abstract}

We recommend the Scott wiring technique to stabilise the direct repair of a lumbar spondylolysis.

Spondylolysis remains the commonest identifiable cause of low back pain in children and adolescents (Hensinger 1989 ) and in young adults. Conservative measures are successful in managing most patients but those who remain symptomatic often benefit from operative treatment.

The surgical solutions include posterior and posterolateral fusion (Bosworth et al 1955; Hensinger 1989). Kimura (1968) described direct repair, which has the theoretical advantage of restoring the anatomy and causing less restriction of spinal movement, with a reduced risk of subsequent instability at adjacent levels. Buck (1970) stabilised his repair with screws but stressed the technical difficulties of accurate screw placement (Buck 1979).

Nicol and Scott (1986) developed a wiring technique to stabilise the repaired defects. They used the procedure for spondylolysis at one or more levels in patients under 30 years old and recommended it especially for lesions at the L4 level. The technique was said to be simple and less technically demanding than a Buck fusion. The upper age limit was subsequently reduced to 25 years (Scott 1987).

Bradford and Iza's report (1985) on the Scott technique stressed an upper age limit of 30 years. They

G. V. Johnson, FRCS Ed, Senior Registrar

A. G. Thompson, FRCS Ed, Consultant Orthopaedic Surgeon

Royal Orthopaedic Hospital, Woodlands, Bristol Road South, Northfield, Birmingham B31 2AP, England.

Correspondence should be sent to Mr A. G. Thompson.

(C) 1992 British Editorial Society of Bone and Joint Surgery

$0301-620 \mathrm{X} / 92 / 3335 \$ 2.00$

J Bone Joint Surg [Br] 1992; 74-B : 426-30. achieved excellent results in patients with defects between $\mathrm{Ll}$ and $\mathrm{L} 4$ with minimal slip.

We report our results in a similar group of patients and review the indications for this procedure.

\section{PATIENTS AND METHODS}

Patient selection. All patients had radiologically confirmed spondylolysis, with spondylolisthesis of not more than grade I (Meyerding 1932). They had considerable restriction of activities because of chronic low back pain. Conservative measures continued for at least six months, and including rest, avoidance of sport, a plaster jacket or lumbar corset, analgesics and physiotherapy, had failed to give relief.

Operative technique. The patient lies prone on a Toronto frame. Through a posterior longitudinal midline incision, extending between the adjacent spinous processes, the paravertebral muscles are stripped to expose the spinous processes, laminae and both transverse processes, leaving the facet joints and their capsules undisturbed. The soft tissues attached to the anterior aspect of the transverse processes are carefully elevated, avoiding the nerve roots which lie ventrally (Fig. 1). The presence of bilateral pars interarticularis defects is confirmed by demonstrating abnormal movement at these sites when adjacent spinous processes are rotated in the transverse plane.

The defects are then cleared of fibrous and cartilaginous tissue. The underlying nerve can be decompressed at this stage through a limited laminotomy if indicated. The sclerotic bony margins of the defects are curetted to expose healthy bone (Fig. 2) and the base of the transverse process, the lateral aspect of the superior facet, and the lamina are gently decorticated on each side. 


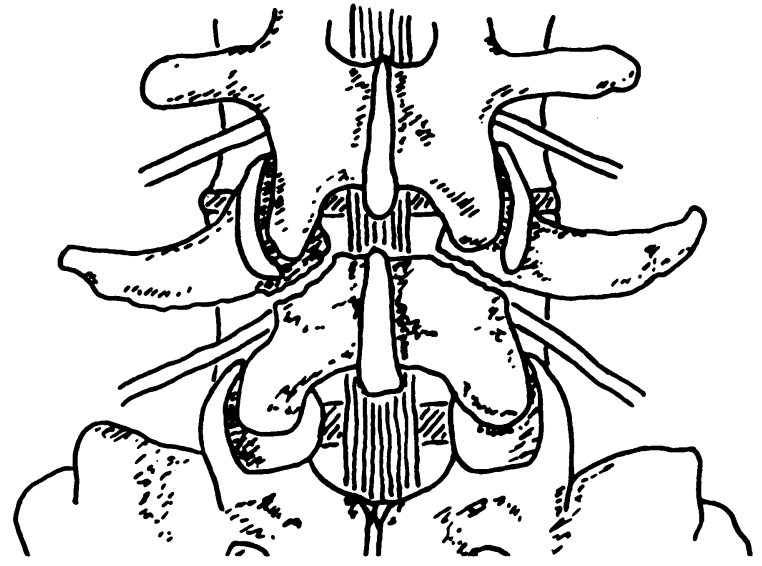

Fig. 1

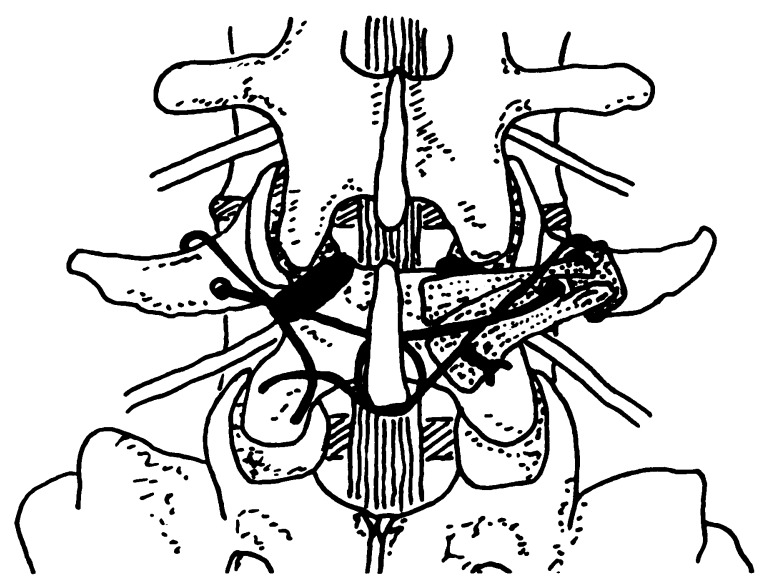

Fig. 3

A $2 \mathrm{~mm}$-diameter hole is drilled in the base of each transverse process through which a $15 \mathrm{~cm}$ length of 20 gauge braided wire is passed and curled superiorly over the transverse process (Fig. 2). A 4 mm-diameter hole is then drilled in the base of the spinous process through which both wires are passed so that each makes a figureof-eight with the cross-over at the defect (Fig. 2).

Through a subcutaneous extension of the wound, one posterior iliac crest is partially exposed. Four corticocancellous bone strips, $1.0 \mathrm{~cm} \times 2.5 \mathrm{~cm}$, are taken from the outer table of the iliac wing. Six 'caterpillars' of cancellous bone are removed with a gouge and are gently packed into the defects, taking care not to compress the underlying nerve roots (Fig. 3). Two bone strips are then placed beneath the wires across each defect so that they lie over the decorticated areas of the transverse process, the superior facet and the lamina. The wires are tightened to hold the underlying bone grafts in place (Fig. 3) and to stabilise the defect. Absence of movement at the defects on rotation of the spinous processes should now be demonstrated.

After a satisfactory radiograph at two days (Fig. 4), the patient is mobilised with a light removable brace, which is worn for three months. Activities are restricted

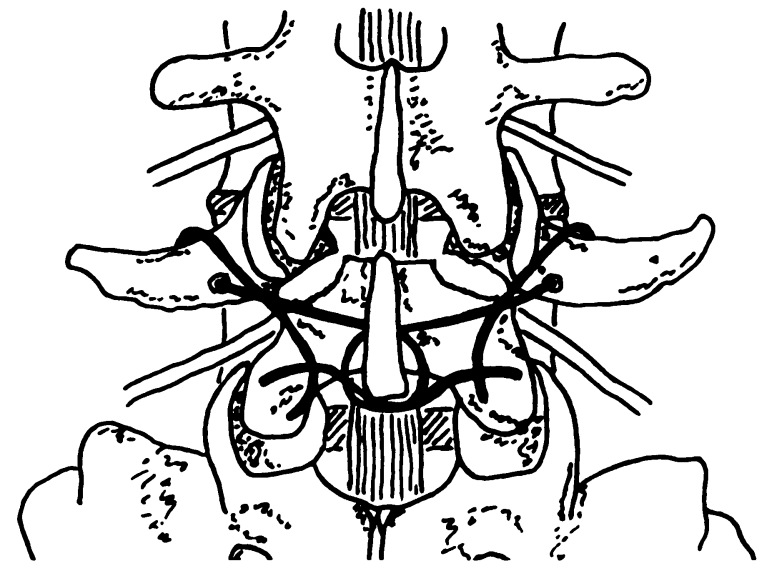

Fig. 2

Figure 1 - The anatomy of the lumbosacral region to show the relationship between the transverse process and the nerve root. Figure 2 - The defects have been curetted and holes drilled in the transverse and spinous processes. The braided wire is in position. Figure 3 - On the left the defect has been packed with cancellous graft (black). On the right, corticocancellous onlay grafts extend from the transverse process to the lamina. The wire has been tightened to secure the grafts.

Table I. Subjective assessment guidelines (after Henderson 1966)

\begin{tabular}{ll}
\hline Grade & Description \\
\hline Excellent & $\begin{array}{l}\text { No pain, return to normal occupation and } \\
\text { normal sport }\end{array}$ \\
Good & $\begin{array}{l}\text { Occasional pain after strenuous activity, return } \\
\text { to normal occupation and less strenuous sport }\end{array}$ \\
Poor & $\begin{array}{l}\text { Pain persists, unable to return to occupation and } \\
\text { to partake in sport }\end{array}$ \\
\hline
\end{tabular}

until the defect is shown to have united radiologically and on a CT scan (Fig. 5) (McAfee and Yuan 1982), usually about six months after the operation. Thereafter, patients can return to normal activities.

Assessment. We reviewed all patients using a modified version of the subjective assessment described by Henderson (1966). The presence of residual pain and ability to return to normal work or school and sporting activities were used to measure the result (Table I).

\section{RESULTS}

Between 1979 and 1989 we performed the operation as described above on 22 patients. All were available for review. There were seven women and 15 men. The average time from the onset of symptoms to the operation 


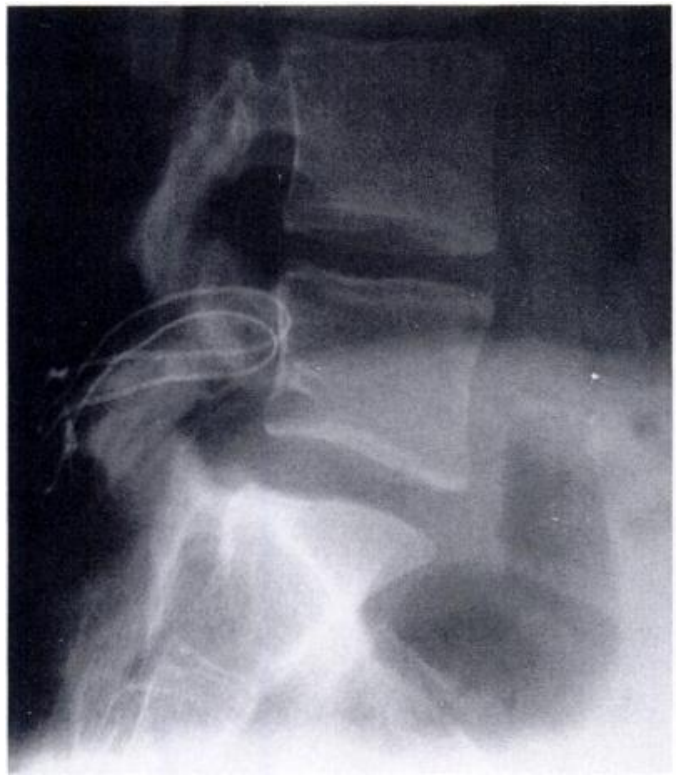

Fig. 4a

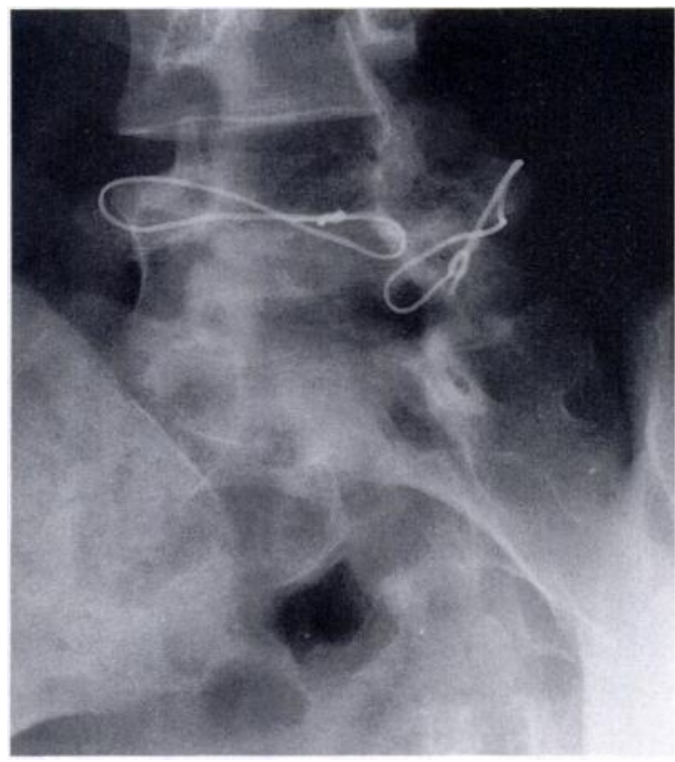

Fig. 4c

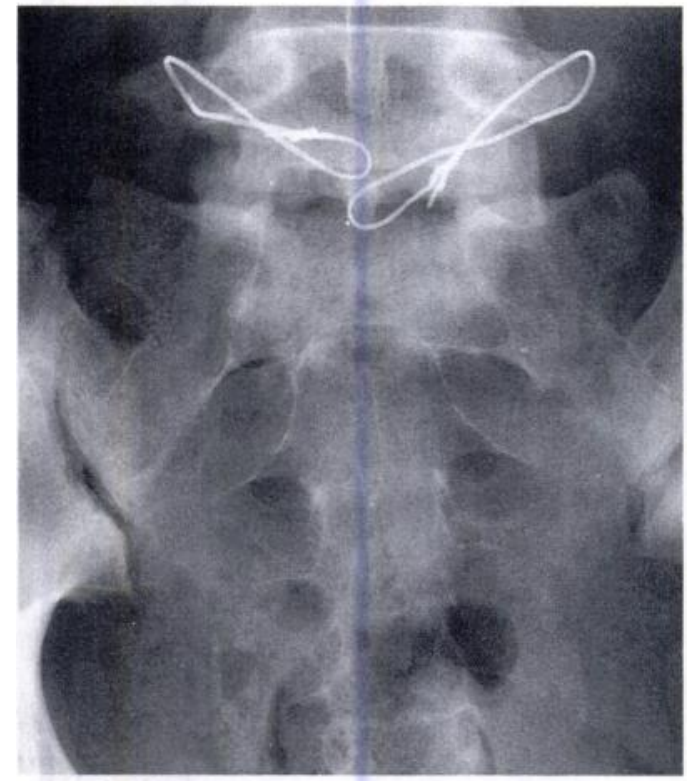

Fig. 4b

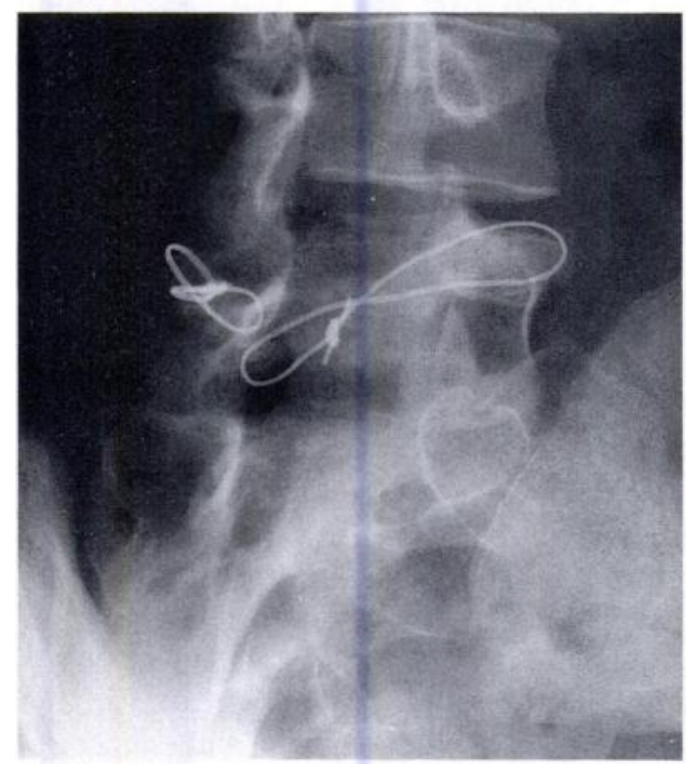

Fig. 4d

Anteroposterior (a), lateral (b) and oblique (c,d) radiographs to show the postoperative appearances.

was three years. The mean age of the patients at operation was 15.5 years; the mean follow-up period was four years. The lytic defects were at L5 in 21 patients and at L4 in one. The defects were bilateral in 20 ; the two unilateral defects were at L5. No patient had defects at more than one level.

Satisfactory results were recorded in 20 of the 22 patients, 16 excellent and four good.

Two patients were not improved by surgery. One, who was 25 years old, had good pain relief for six months but then developed recurrence of low back pain. He underwent a further surgical procedure, recovery from which was prolonged. The second patient, who was 30 years old, had persistent pain and subsequently underwent an intersegmental fusion.

Fusion. All the 17 patients whose defects healed had excellent (14) or good (three) results. They included both patients with unilateral defects. There was unilateral healing in three patients with bilateral defects, an excellent result in one (aged 15 years), a good result in one (aged 16 years) and a poor result in one (aged 25 years). In two patients the defects did not fuse. One (aged 13 years) had an excellent result, and the other (aged 30 years) a poor result.

Age. All 19 patients under 25 years old had excellent (17) or good (two) results, despite incomplete or failed fusion 
of the defects in three. Of the three patients over 25 years old, two had poor and one a good result.

Spondylolisthesis. The presence of a grade I slip did not seem to influence the outcome adversely. There were four patients with no slip and the rest had a grade I slip. One of the patients (aged 25 years) with a poor result had no slip and the other (aged 30 years) had a grade I slip. Only one patient had an increase in the slip after surgery; she had a good result.

Postoperative complications included urinary retention (two), superficial wound infection (two), wire rupture (two) and donor site pain (three). All these patients achieved a satisfactory result. The wire pulled out in one patient, the 30-year-old with a poor result.

\section{DISCUSSION}

The source of pain in young patients with spondylolysis appears to be the pseudarthroses. It has been suggested that as these patients reach early adulthood, secondary changes occur in the adjacent discs, and their low back pain may then be discogenic in origin. The results of this series of patients would support this premise. All 19 patients under 25 years old had satisfactory results.

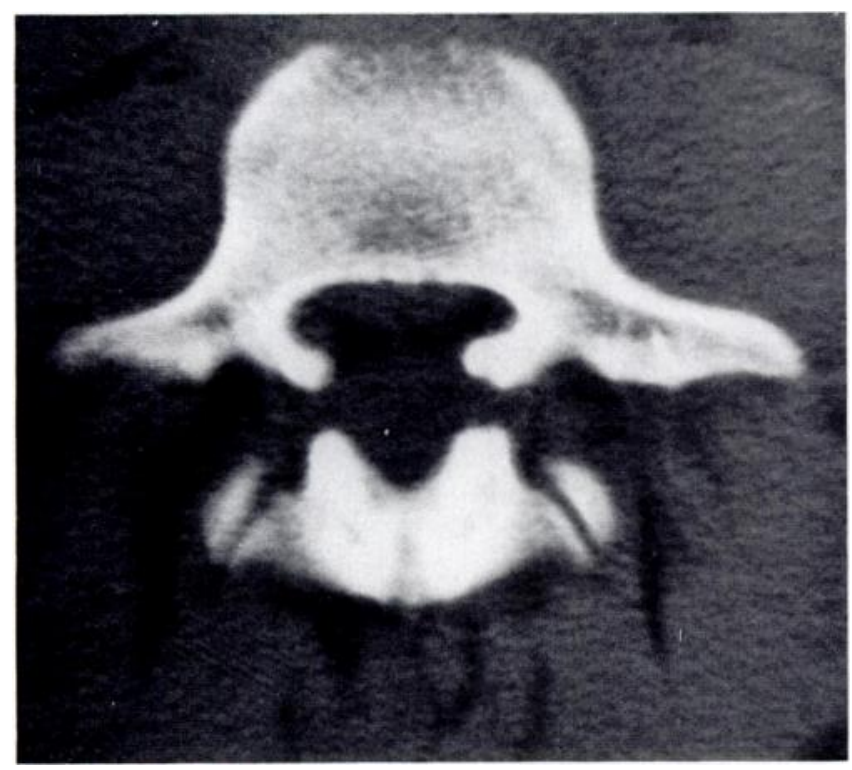

Fig. 5a the nerve root to the lower border of the transverse process, we pass the wire through a small drill hole in the base of the transverse process, and then curl it over the upper border of that transverse process (Fig. 2). Braided wire is preferred because it is more malleable than monofilament wire, and easier to handle. It did not prove to be more prone to breakage. We also pass the wires through, rather than around, the base of the spinous process as this gives better purchase. There were no fractures of transverse or spinous processes. We think that it is important to demonstrate, on the table, that the lytic defects are stable after wiring.

The best early results of some other techniques are similar to ours (Buck 1970; Turner and Bianco 1971; Buring and Fredensborg 1973; Pederson and Hagen 1988). The surgical exposure required for the Scott wiring technique is slightly greater than with the Buck method, but its relative safety and simplicity make it more attractive than screw fusion (Pederson and Hagen 1988).

Olsson, Selvik and Willner (1976) and Kumar (1986) have shown that there is a slight decrease in range of lumbar spinal movements after a Scott fusion. After intersegmental fusion, however, spinal mobility is even more restricted. Although the subsequent development

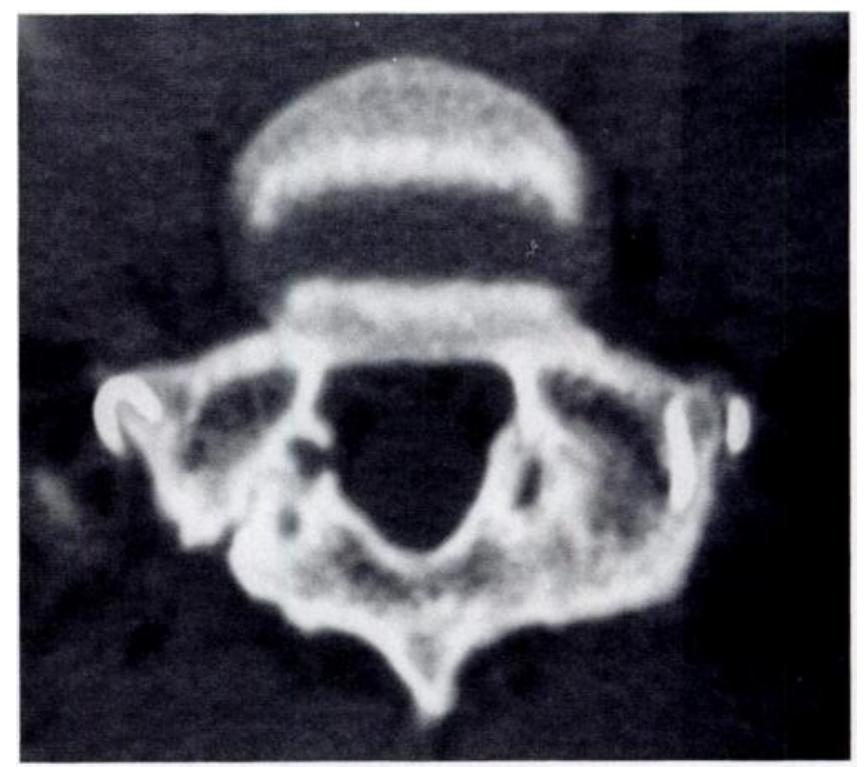

Fig. $5 b$

CT scans showing satisfactory healing of bilateral lytic defects.

Our experience is comparable to that of Bradford and Iza (1985), Nicol and Scott (1986) and Scott (1987) using similar wiring techniques. The operations, however, were mainly at higher lumbar levels. We have shown that similar results can be obtained with this technique at L5.

We have modified Scott's technique to improve its safety and simplicity. Because of the close proximity of of symptoms from degenerative changes at adjacent levels has not been quantified, there is a risk of this following intersegmental fusion.

The Scott fusion is applicable to patients under 25 years old whose symptoms persist after conservative treatment for 12 months. Older patients, in whom discography or MRI shows normal discs, may also be candidates for direct repair of lytic defects. In the 
presence of abnormal discs, intersegmental fusion is probably to be preferred. While the surgical aim is fusion, the failure to achieve this did not necessarily mean a poor result. Of the five patients in whom fusion for bilateral defects had been successful only on one side, the three under 25 years old had satisfactory results. This suggests that age is the main determinant of outcome, and that successful fusion is of secondary importance. The presence of minimal slip did not prejudice the results.

The precise cause of spondylolysis remains uncertain, but current opinion is that there is an element of genetically-determined weakness or dysplasia at the pars interarticularis, which renders it unable to withstand the stresses of normal activity, resulting in a stress fracture. The direct-repair technique aims to convert this weak point into a strong bone bridge, so that recurrence of the lysis is unlikely. Perhaps the adjacent disc degeneration, commonly seen in adult life in patients with untreated spondylolysis, will thereby be avoided.

We believe that, where applicable, the Scott wiring technique to stabilise a direct repair of lumbar spondylolysis is the procedure of choice.

No benefits in any form have been received or will be received from a commercial party related directly or indirectly to the subject of this article.

\section{REFERENCES}

Bosworth DM, Fielding JW, Demarest L, Bonaquist M. Spondylolisthesis: a critical review of a consecutive series of cases treated by arthrodesis. J Bone Joint Surg [ Am] 1955; 37-A :767-86.

Bradford DS, Iza J. Repair of the defect in spondylolysis or minimal degrees of spondylolisthesis by segmental wire fixation and bone grafting. Spine 1985; 10(7):675-8.

Buck JE. Direct repair of the defect in spondylolisthesis: preliminary report. J Bone Joint Surg [Br] 1970; 52-B:432-7.

Buck JE. Further thoughts on direct repair of the defect in spondylolysis. J Bone Joint Surg [Br] 1979; 61-B:123.

Buring K, Fredensborg N. Osteosynthesis of spondylolysis. Acta Orthop Scand 1973; 44:91

Henderson ED. Results of the surgical treatment of spondylolisthesis. J Bone Joint Surg [ Am] 1966; 48-A :619-42.

Hensinger RN. Spondylolysis and spondylolisthesis in children and adolescents: current concepts review. J Bone Joint Surg [Am] 1989; 71-A:1098-107.

Kimura M. My method of filling the lesion with spongy bone in spondylolysis and spondylolisthesis. Orthop Surg 1968; 19:285-95 [in Japanese].
Kumar S. Spondylolysis and Grade I spondylolisthesis: a review of Scott's and Buck's fusions. MCh(Orth) Thesis, University of Liverpool, 1986.

McAfee PC, Yuan HA. Computed tomography in spondylolisthesis. Clin Orthop 1982:166:62-71.

Meyerding HW. Spondylolisthesis. Surg Gynecol Obstet 1932; 54: 371-7.

Nicol RO, Scott JH. Lytic spondylolysis: repair by wiring. Spine 1986; $11: 1027-30$.

Olsson TH, Selvik G, Willner S. Vertebral motion in spondylolisthesis. Acta Radiol (Diagn) [Stockh] 1976; 17:861-8.

Pederson AK, Hagen R. Spondylolysis and spondylolisthesis : treatment by internal fixation and bone grafting of the defect. $J$ Bone Joint Surg [ Am] 1988; 70-A :15-24.

Scott JHS. The Edinburgh repair of isthmic (Group II) spondylolysis. J Bone Joint Surg [Br] 1987; 69-B:491.

Turner RH, Bianco AJ Jr. Spondylolysis and spondylolisthesis in children and teen-agers. J Bone Joint Surg [Am] 1971; 53-A: 1298-306. 